Www.jmscr.igmpublication.org

Impact Factor (SJIF): 6.379

Index Copernicus Value: 79.54

ISSN (e)-2347-176x ISSN (p) 2455-0450

crossrefDOI: https://dx.doi.org/10.18535/jmscr/v6i10.195

Journal Of Medical Science And Clinical Research

\title{
Clinical study of panretinal photocoagulation in the treatment of diabetic retinopathy using laser indirect ophthalmoscopy
}

Authors

\section{Nithya $M^{1}$, Mishra $P^{2}$, Manavalan $S^{3}$, Sridevi $V^{4}$, Ramya $M^{5}$}

${ }^{1}$ Postgraduate, Department of Ophthalmology, Rajah Muthiah Medical College and Hospital,

Annamalai University, Annamalai Nagar - 608002

${ }^{2}$ Professor \& HOD, Department of Ophthalmology, Rajah Muthiah Medical College and Hospital,

Annamalai University. Annamalai Nagar - 608002

${ }^{3}$ Professor, Department of Ophthalmology, Rajah Muthiah Medical College and Hospital,

Annamalai University. Annamalai Nagar - 608002

${ }^{4}$ Associate Professor, Department of Ophthalmology, Rajah Muthiah Medical College and Hospital,

Annamalai University. Annamalai Nagar - 608002

${ }^{5}$ Senior Resident, Department of Ophthalmology, Rajah Muthiah Medical College and Hospital, Annamalai

University. Annamalai Nagar - 608002

\begin{abstract}
Background: The diode laser is a solid state laser with wavelength of $532 \mathrm{~nm}$ that produces photocoagulation. It is a technique used in the treatment of diabetic retinopathy. Diabetic retinopathy occurs as a microvascular complication of systemic diabetes which produces hemorrhages, neovascularisation in the retina and if left untreated can lead to vision threatening complications like vitreous hemorrhage, retinal detachment.

Objective: To study the efficacy and complications of Panretinal Photocoagulation in the treatment of severe nonproliferative and early proliferative diabetic retinopathy.

Material and Methods: This prospective clinical study was conducted in the Department of Ophthalmology at Rajah Muthiah Medical College and Hospital, Chidambaram from October 2016 to September 2018 on 100 eyes of 50 patients with diabetic retinopathy who underwent Panretinal Photocoagulation using diode pump solid state (DPSS) OCULIGHT GL 532nm. The patients were assessed for post laser best corrected visual acuity at 1 week and 6 months.

Results: Out of 50 patients 31(62\%) were males and 19(38\%) were females. The mean age of the patients in the study was 57years. Most of the patients in the study were in the age group between 51 and 60 years (44\%). The mean duration of diabetes was 6 to 10 years (34\%). The mean BCVA of BE before laser treatment and after laser treatment showed significant reduction at 1 week, which improved at 6 months to pre laser VA and $96 \%$ patients had stable vision and only $4 \%$ showed decrease in BCVA due to persistence of PDR and they developed vitreous hemorrhage.

Conclusion: The Panretinal Photocaogulation is a safe, effective outpatient procedure for the treatment of severe non proliferative and proliferative diabetic retinopathy.

Keywords: panretinal photocoagulation, severe nonproliferative diabetic retinopathy, proliferative diabetic retinopathy, best corrected visual acuity.
\end{abstract}




\section{Introduction}

Diabetic Retinopathy (DR) is a micro vascular complication of diabetes in which elevated blood sugar levels damage the retinal vasculature. According to World Health Organization (WHO), Diabetic Retinopathy contributes to $5 \%$ of world blindness ${ }^{1}$. Diabetic retinopathy is the $5^{\text {th }}$ leading cause of blindness ${ }^{2}$. The global prevalence of diabetic retinopathy (DR) and proliferative diabetic retinopathy (PDR) in diabetes were $35.4 \%$ and $7.5 \%$ respectively $^{2}$. In India, the prevalence of DR is $18 \%{ }^{2}$.

Pan Retinal Photocoagulation (PRP) is the gold standard treatment for Diabetic retinopathy. It prevents the severity and complications that lead to blindness. It is cost effective, less invasive and performed as outpatient procedure and reduces the duration of hospital stay when compared to the recent modalities of treatment for diabetic retinopathy.

According to literature there was an increase in diabetes prevalence and their complications especially diabetic retinopathy resulting in blindness. There was paucity of Indian studies available in the literature about diabetic retinopathy in patients who underwent panretinal photocoagulation. To know the outcome of diabetic retinopathy in patients who underwent panretinal photocoagulation, this study was undertaken.

\section{Aims}

To assess the effects of laser panretinal photocoagulation for patients having Diabetic Retinopathy with severe nonproliferative and proliferative changes.

\section{Objective}

i. To observe the clinical outcomes of laser panretinal photocoagulation in Diabetic Retinopathy patients having severe nonproliferative and proliferative changes.

ii. To observe the complications of laser panretinal photocoagulation in Diabetic
Retinopathy patients having severe nonproliferative and proliferative changes.

\section{Materials}

Study Design: Prospective Clinical Study

Study Place: Ophthalmology Department, Rajah Muthiah Medical College and Hospital (RMMCH), Chidambaram.

Study Duration: 2 years (October 2016 September 2018)

Target Population: Patients with Diabetic Retinopathy attending Ophthalmology Department at RMMCH.

Study Population: Patients with Diabetic Retinopathy who underwent Panretinal photocoagulation in the Ophthalmology Department at RMMCH.

Inclusion criteria: Patient with Diabetic Retinopathy

i) Having severe nonproliferative and proliferative type involving retina and optic disc and

ii) Whose visual acuity at initial assessment is not less than $6 / 36$ in the proposed eye for treatment.

Exclusion criteria: Patient with Diabetic Retinopathy

i) Having advanced stage of proliferative retinopathy,

ii) Whose visual acuity was adversely affected by opacities of the media and

iii) Associated with complications like maculopathy, extraocular complications and nephropathy.

\section{Methodology}

\section{Selection and Allocation method}

Patients with Diabetic retinopathy attending Ophthalmology Department at Rajah Muthiah Medical College and Hospital (RMMCH), Chidambaram were the target population for the study. Based upon the inclusion criteria study population were enrolled for the study after getting informed consent and their details of personal information, history, examination, 
investigations, treatment and follow-up were taken.

A total of 100 eyes of 50 patients were included. Visual acuity for all patients was evaluated by Snellen's chart.

The patients were then examined under Slit lamp Biomicroscope to rule out anterior segment diseases that could alter the visual outcome.

The posterior segment examination was done with binocular indirect ophthalmoscope and 20D lens with a fully dilated pupil and was diagnosed according to the ETDRS classification for diabetic retinopathy.

IOP was checked using TOPCON non-contact tonometer.

Basic clinical investigations for assessing the current diabetic status of the patients were done.

Patients were then treated with IRIDEX DPSS OCULIGHT-GL. Panretinal photocoagulation delivered using indirect ophthalmoscope with 20 $D$ lens under LA in the Department of Ophthalmology at Rajah Muthiah Medical College and Hospital after obtaining informed written consent.

Panretinal photocoagulation was done in three sitting at weekly interval for all the study population. The inferior half of the retina was photocoagulated first, thus if the eye develops vitreous hemorrhage between sessions, it will settle to the inferior quadrant. The temporal, nasal and superior quadrants are photocoagulated in the following sessions.

Laser settings

- Duration - 0.05-0.1sec

- Spot size - 300-500 microns

- Intensity - moderate

- 1 burn width apart, 3000u from centre of macula and 500u from temporal margin of disc

Patients were reassessed after $1^{\text {st }}$ week and 6 months of post laser PRP and VA recorded using Snellen's chart and corresponding ETDRS score were assigned for the purpose of statistical analysis.

Statistical analysis: All the data were entered in the case proforma for each patient and the data collected was entered into Microsoft Excel Sheet and statistical analysis was arrived by using IBM SPSS software. Statistical methods like frequencies in number and percentage, Mean $\pm \mathrm{SD}$ (SE), P value were used wherever applicable.

\section{Results}

Demography

Total Study Population: 50; Age groups present in the study: 40 to 80 years; Overall Mean \pm SD (SE) age in the study: 57.21 $\pm 8.84(1.25)$ years.

Table 1 Age wise distribution in Diabetic Retinopathy

\begin{tabular}{|c|c|c|c|c|c|c|}
\hline $\begin{array}{l}\text { Age } \\
\text { groups } \\
\text { (years) }\end{array}$ & Number & Percentage & Mean & $\begin{array}{l}\text { Standard } \\
\text { deviation }\end{array}$ & $\begin{array}{l}\text { Standard } \\
\text { error of } \\
\text { mean }\end{array}$ & P Value \\
\hline $40-50$ & 12 & 24 & \multirow{5}{*}{12.50} & \multirow{5}{*}{ \pm 7.70} & \multirow{5}{*}{3.88} & \multirow{5}{*}{0.05} \\
\hline $51-60$ & 22 & 44 & & & & \\
\hline $61-70$ & 13 & 26 & & & & \\
\hline $71-80$ & 3 & 6 & & & & \\
\hline Total & 50 & 100 & & & & \\
\hline
\end{tabular}

The age wise distribution of patients was shown in Table.1. Maximum no of patients were in the age group between 51 and 60 years. About 22 patients belong to this group constituting $44 \%$ of total cases. 
Table.2 Gender distribution in Diabetic Retinopathy

\begin{tabular}{|l|c|c|c|c|c|c|}
\hline Gender & Number & Percentage & Mean & $\begin{array}{c}\text { Standard } \\
\text { deviation }\end{array}$ & $\begin{array}{c}\text { Standard } \\
\text { error of } \\
\text { mean }\end{array}$ & P Value \\
\cline { 1 - 3 } Male & 31 & 62 & \multirow{2}{*}{25.00} & \pm 8.49 & 6.00 & 0.15 \\
\cline { 1 - 3 } & 19 & 38 & & & & \\
\hline Total & 50 & 100 & & & & \\
\hline
\end{tabular}

A total of 50 patients were treated, of which 31 were male and 19 were female as showed in Table.2. Male patients outnumbered female patients. Majority of the people were from a low socio economic background.
Overall Mean $\pm \mathrm{SD}(\mathrm{SE})$ Duration of Diabetes mellitus in study: 11.8 $\pm 6.33(0.90)$ years.

Table.3 Duration of Diabetes Mellitus in Diabetic Retinopathy

\begin{tabular}{|c|c|c|c|c|c|c|}
\hline Duration (years) & Number & Percentage & Mean & $\begin{array}{l}\text { Standard } \\
\text { deviation }\end{array}$ & $\begin{array}{c}\text { Standard error } \\
\text { of mean }\end{array}$ & $\begin{array}{c}P \\
\text { Value }\end{array}$ \\
\hline$\leq 5$ & 11 & 22 & \multirow{6}{*}{10.00} & \multirow{6}{*}{5.00} & \multirow{6}{*}{2.24} & \multirow{6}{*}{0.01} \\
\hline $6-10$ & 17 & 34 & & & & \\
\hline $11-15$ & 10 & 20 & & & & \\
\hline $16-20$ & 9 & 18 & & & & \\
\hline$>20$ & 3 & 6 & & & & \\
\hline Total & 50 & 100 & & & & \\
\hline
\end{tabular}

Out of the 50 patients in the study, 17(34\%) had duration of diabetes mellitus between 6 and 10 years, as shown in Table.3.

\section{Pan Retinal Photocoagulation (PRP)}

\section{Retinal Findings}

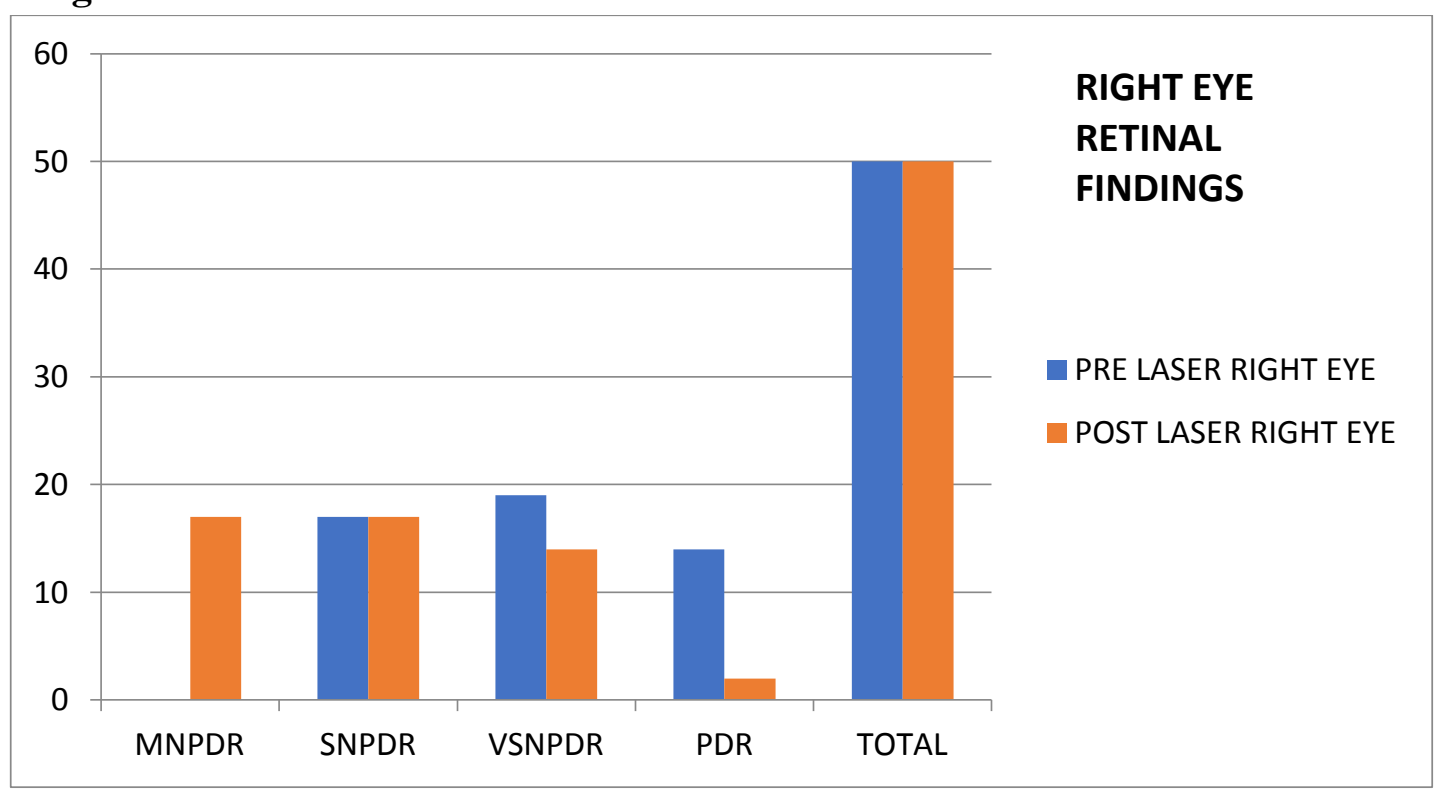

Fig.1.Right eye - Pre and Post Laser fundus findings in study population 
Table.4 Right eye - Pre and Post Laser fundus findings in study population

\begin{tabular}{|c|c|c|c|c|c|}
\hline Right Eye & \multicolumn{2}{|c|}{ Pre laser } & \multicolumn{2}{|c|}{ Post laser } & \multirow[b]{2}{*}{$P$ value } \\
\hline Fundus findings & Number & Percentage & Number & Percentage & \\
\hline MNPDR & 0 & 0 & 17 & 34 & \multirow{5}{*}{1.00} \\
\hline SNPDR & 17 & 34 & 17 & 34 & \\
\hline VSNPDR & 19 & 38 & 14 & 28 & \\
\hline PDR & 14 & 28 & 2 & 4 & \\
\hline Total & 50 & 100 & 50 & 100 & \\
\hline
\end{tabular}

As depicted in Fig.1 and Table.4. In the right eye PDR was present in 14 patients before laser treatment, which constitute about $28 \%$ showed regression to only 2 patients which constitute $4 \%$ after laser treatment and the remaining $72 \%$ percent patients showed regression from VSNPDR and SNPDR to either SNPDR or MNPDR after laser treatment which constitute $68 \%$.

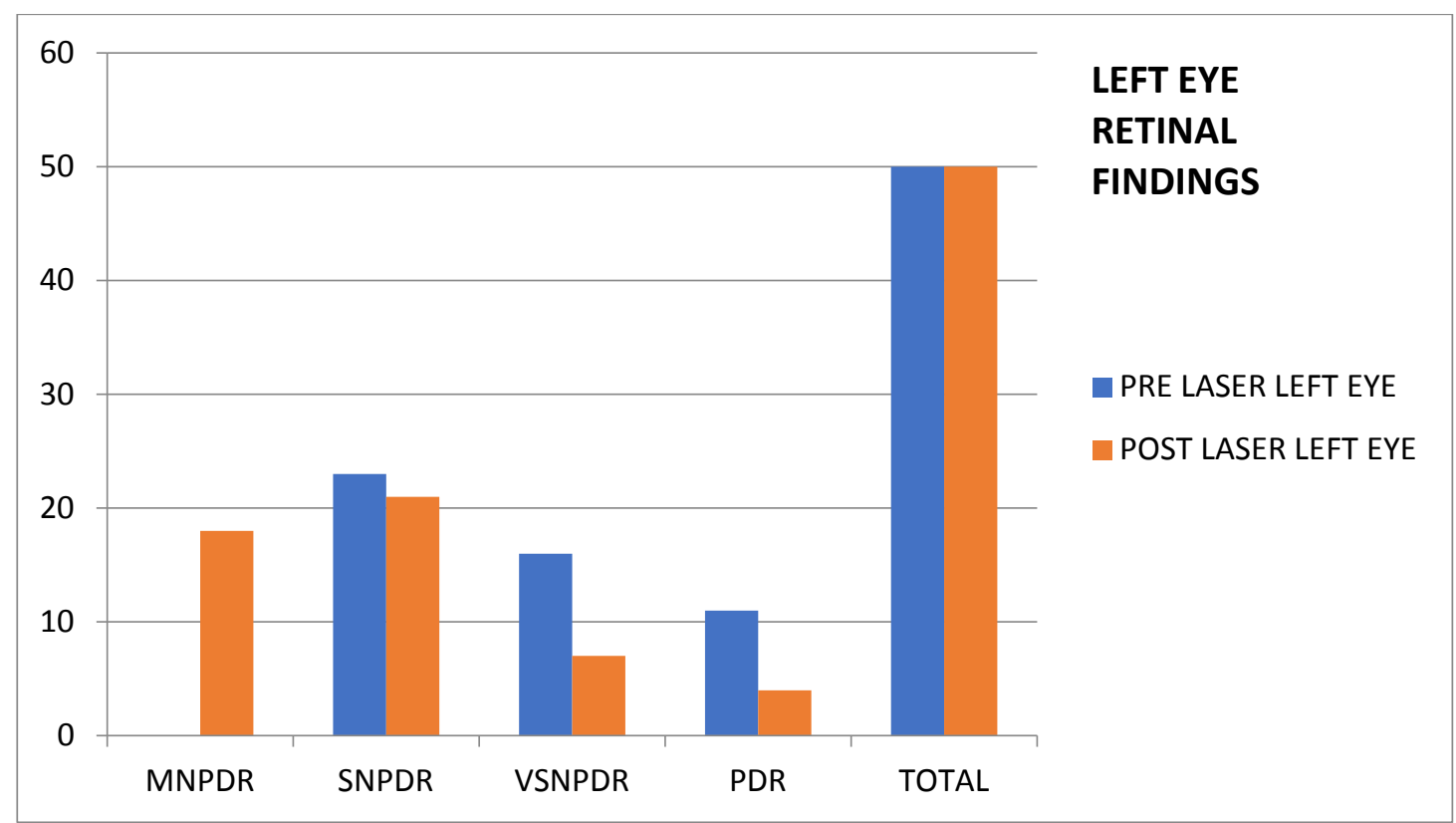

Fig.2 Left eye - Pre and Post Laser fundus findings in study population

Table.5 Left eye - Pre and Post Laser fundus findings in study population

\begin{tabular}{|c|c|c|c|c|c|}
\hline Left Eye & \multicolumn{2}{|c|}{ Pre laser } & \multicolumn{2}{|c|}{ Post laser } & \multirow{2}{*}{$P$ value } \\
\hline Fundus findings & Number & Percentage & Number & Percentage & \\
\hline MNPDR & 0 & 0 & 18 & 36 & \multirow{5}{*}{1.00} \\
\hline SNPDR & 23 & 46 & 21 & 42 & \\
\hline VSNPDR & 16 & 32 & 7 & 14 & \\
\hline PDR & 11 & 22 & 4 & 8 & \\
\hline Total & 50 & 100 & 50 & 100 & \\
\hline
\end{tabular}

As depicted in Fig.2 and Table.5. In the left eye PDR was present in 11 patients before laser treatment, which constitute about $22 \%$ showed regression to 4 patients who constitute $8 \%$ after laser treatment and the remaining $78 \%$ percent patients showed regression from VSNPDR and SNPDR to either SNPDR or MNPDR after laser treatment which constitute $78 \%$. 


\section{ETDRS Score}

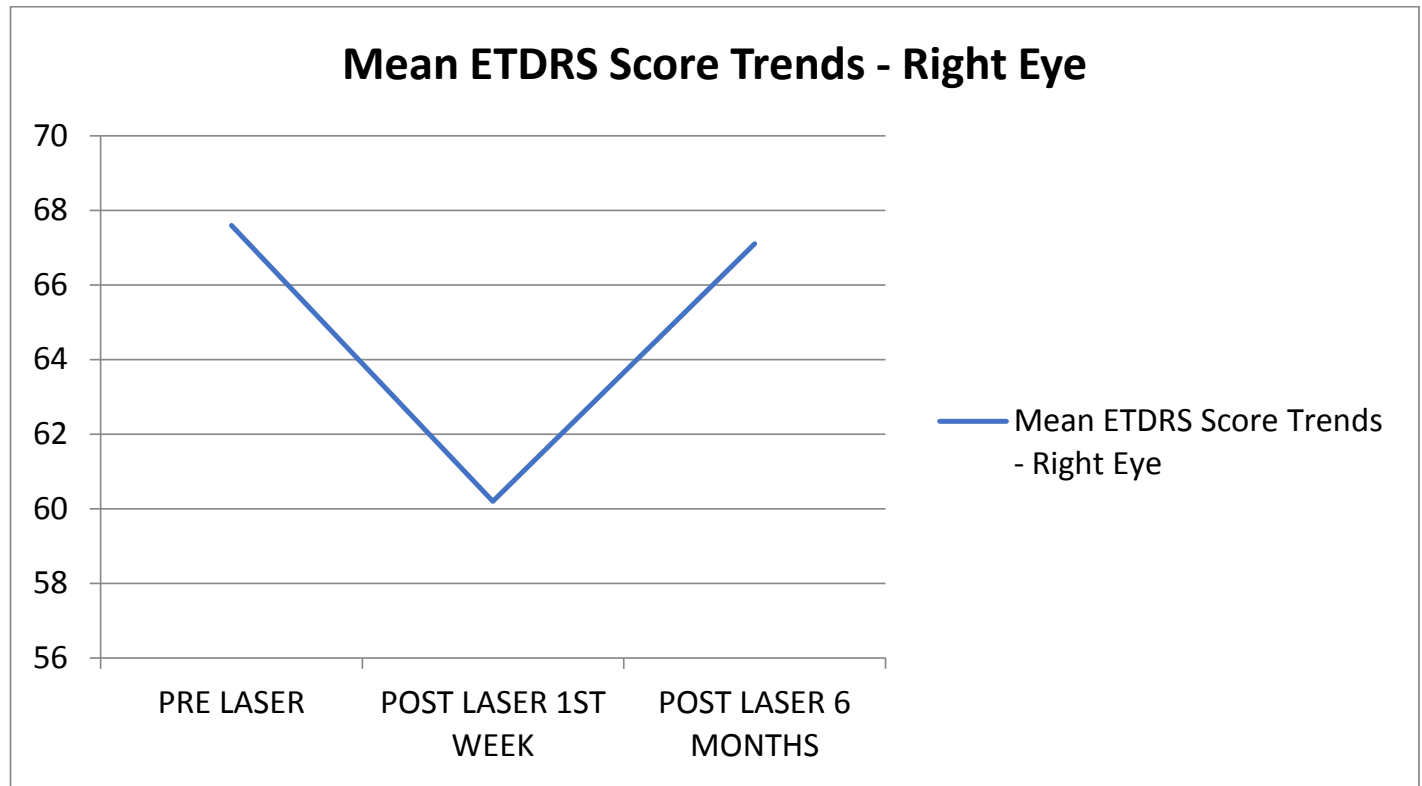

Fig.3 Mean ETDRS score trends in right eye in study population

Table.6. Mean ETDRS score in right eye in study population

\begin{tabular}{|l|c|c|c|c|c|}
\hline Right Eye ETDRS Score & Number & Percentage & Mean & $\begin{array}{c}\text { Standard } \\
\text { Deviation }\end{array}$ & Standard Error of Mean \\
\hline Pre Laser & 50 & 100 & 67.60 & \pm 12.91 & 1.83 \\
\hline Post Laser-1 $\mathbf{1}^{\text {st }}$ week & 50 & 100 & 60.20 & \pm 13.44 & 1.90 \\
\hline Post Laser-6 months & 50 & 100 & 67.10 & \pm 13.67 & 1.93 \\
\hline
\end{tabular}

As depicted in Fig. 3 and Table.6. In right eye the mean ETDRS score pre laser was 67.60 and post laser ETDRS score in the $1^{\text {st }}$ week following laser showed significant reduction to about 60.20 and the post laser ETDRS score at 6 months was 67.10 which was not significant when compared to pre laser ETDRS score.

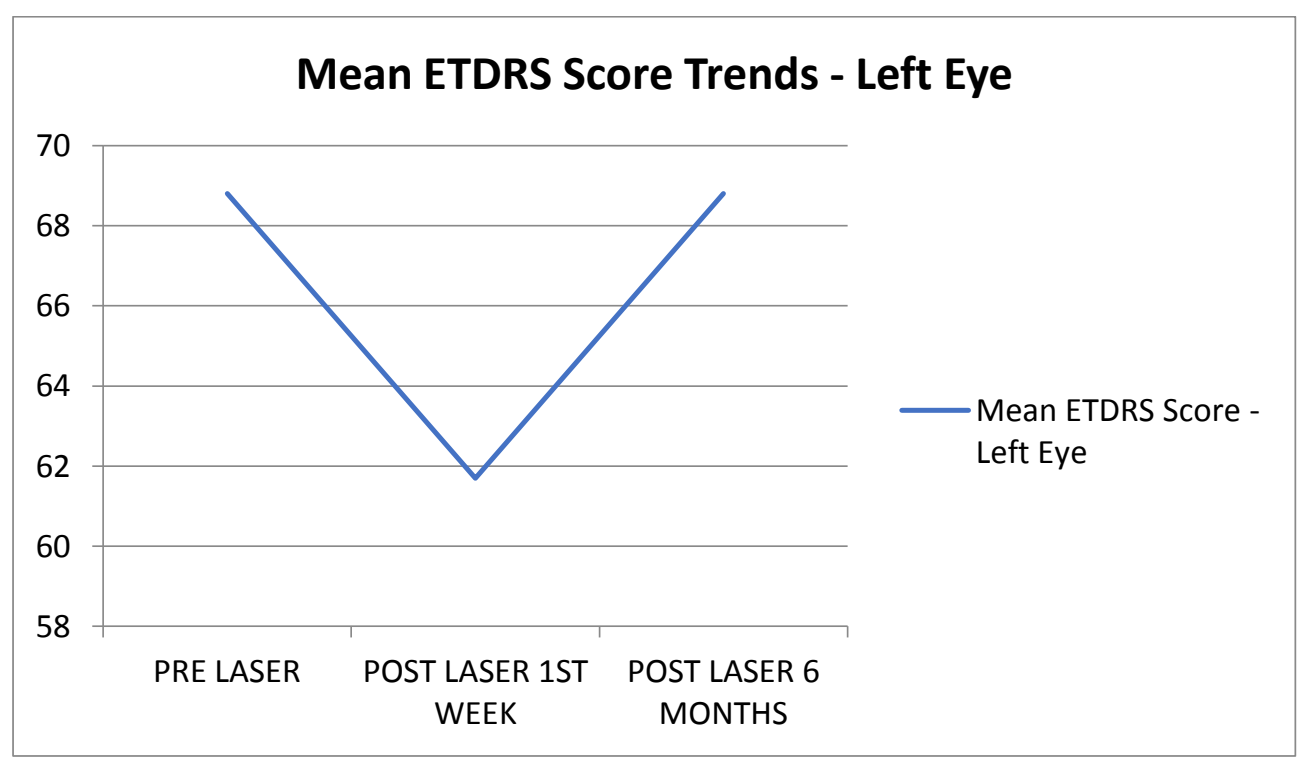

Fig.4 Mean ETDRS score trends in left eye in study population 
Table.7. Mean ETDRS Score in left eye in study population

\begin{tabular}{|l|c|c|c|c|c|}
\hline Left Eye ETDRS Score & Number & Percentage & Mean & $\begin{array}{c}\text { Standard } \\
\text { Deviation }\end{array}$ & $\begin{array}{c}\text { Standard Error of } \\
\text { Mean }\end{array}$ \\
\hline Pre Laser & 50 & 100 & 68.80 & \pm 12.23 & 1.73 \\
\hline Post Laser-1 $\mathbf{1}^{\text {st week }}$ & 50 & 100 & 61.80 & \pm 12.89 & 1.82 \\
\hline Post Laser - 6 months & 50 & 100 & 68.80 & \pm 12.68 & 1.79 \\
\hline
\end{tabular}

As depicted in Fig.4 and Table.7. In left eye the mean ETDRS score pre laser was 67.60 and post laser ETDRS score in the $1^{\text {st }}$ week following laser showed significant reduction to about 60.20 and the post laser ETDRS score at 6 months was 67.10 which was not significant when compared to pre laser ETDRS score.

\section{BCVA}

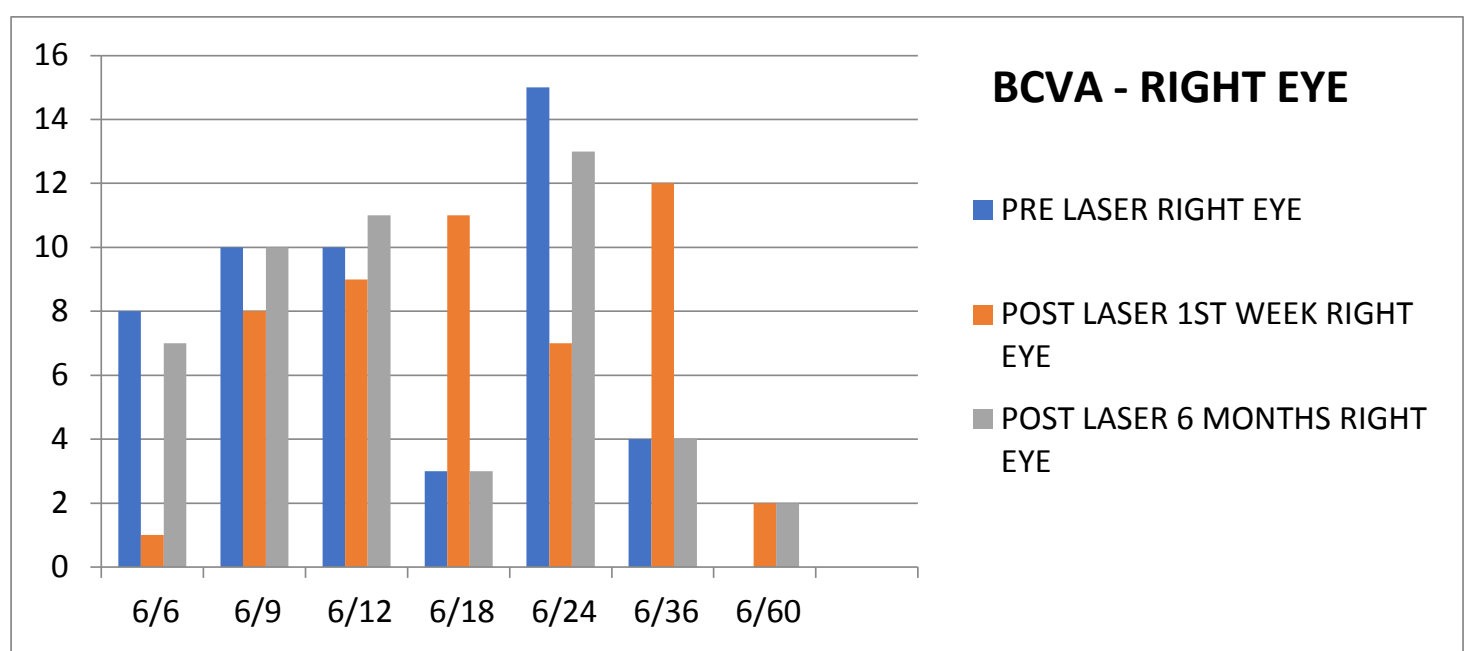

Fig.5 Best Corrected Visual Acuity (BCVA) in Right Eye in study population

Table.8 Comparison between prelaser, postlaser $-1^{\text {st }}$ week $\&$ BCVA in right eye

\begin{tabular}{|c|c|c|c|c|c|c|c|c|}
\hline $\begin{array}{l}\text { RIGHT } \\
\text { EYE }\end{array}$ & \multicolumn{2}{|c|}{ Pre Laser } & \multicolumn{2}{|c|}{$\begin{array}{l}\text { Post Laser }-1^{\text {st }} \\
\text { week }\end{array}$} & \multicolumn{2}{|c|}{$\begin{array}{c}\begin{array}{c}\text { Post Laser - } 6 \\
\text { months }\end{array} \\
\end{array}$} & \multirow{2}{*}{$\begin{array}{c}\text { P value } \\
\text { prelaser } \& \\
\text { postlaser } \\
1^{\text {st }} \text { week }\end{array}$} & \multirow{2}{*}{$\begin{array}{c}\text { P value } \\
\text { prelaser } \& \\
\text { postlaser } 6 \\
\text { months }\end{array}$} \\
\hline BCVA & Number & $\%$ & Number & $\%$ & Number & $\%$ & & \\
\hline $6 / 6$ & 8 & 16 & 1 & 2 & 8 & 16 & \multirow{8}{*}{1.00} & \multirow{8}{*}{1.00} \\
\hline $6 / 9$ & 10 & 20 & 8 & 16 & 10 & 20 & & \\
\hline $6 / 12$ & 10 & 20 & 9 & 18 & 10 & 20 & & \\
\hline $6 / 18$ & 4 & 8 & 11 & 22 & 3 & 6 & & \\
\hline $6 / 24$ & 15 & 30 & 7 & 14 & 15 & 30 & & \\
\hline $6 / 36$ & 3 & 6 & 12 & 24 & 3 & 6 & & \\
\hline $6 / 60$ & 0 & 0 & 2 & 4 & 1 & 2 & & \\
\hline Total & 50 & 100 & 50 & 100 & 50 & 100 & & \\
\hline
\end{tabular}

The BCVA in the right eye showed significant decrease by one line during $1^{\text {st }}$ week of post laser treatment and during the final follow up at 6 months nearly 96 percent of patients regained their prelaser BCVA(Fig.5). As depicted in the
Table.8, from the mean values and the $\mathrm{P}$ value calculated for the BCVA pre laser, $1^{\text {st }}$ week and 6 months in the right eye showed no significant difference. 


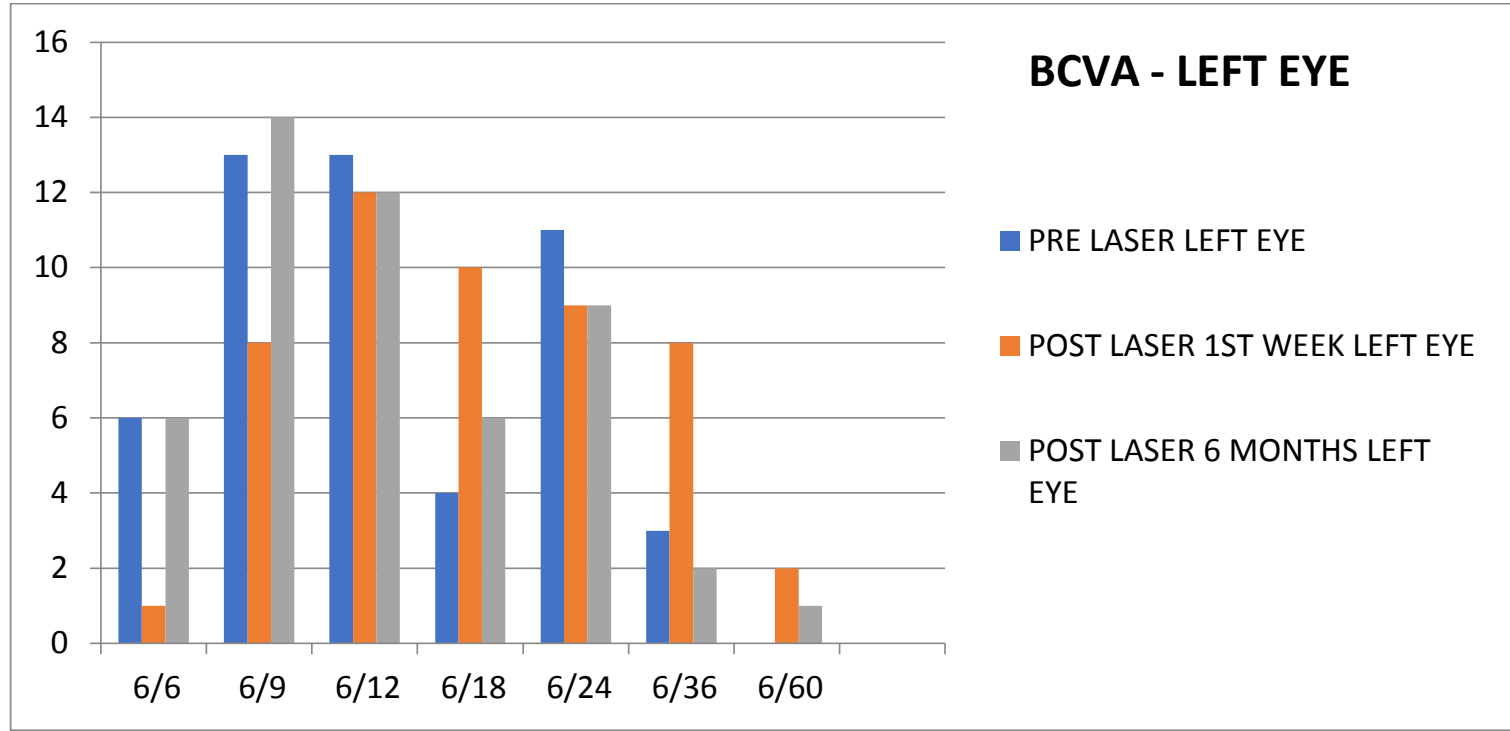

Fig.6. Best Corrected Visual Acuity (BCVA) in left eye in study population

Table.9 Best Corrected Visual Acuity (BCVA) in left eye in study population

\begin{tabular}{|c|c|c|c|c|c|c|c|c|}
\hline $\begin{array}{l}\text { LEFT } \\
\text { EYE } \\
\end{array}$ & \multicolumn{2}{|c|}{ Pre Laser } & \multicolumn{2}{|c|}{$\begin{array}{c}\begin{array}{c}\text { Post Laser }-1^{\text {st }} \\
\text { week }\end{array} \\
\end{array}$} & \multicolumn{2}{|c|}{$\begin{array}{l}\text { Post Laser - } 6 \\
\text { months }\end{array}$} & \multirow{2}{*}{$\begin{array}{c}\text { P value } \\
\text { prelaser \& } \\
\text { postlaser - } \\
1^{\text {st }} \text { week } \\
\end{array}$} & \multirow{2}{*}{$\begin{array}{c}\text { P value } \\
\text { prelaser \& } \\
\text { postlaser } 6 \\
\text { months }\end{array}$} \\
\hline BCVA & Number & $\%$ & Number & $\%$ & Number & $\%$ & & \\
\hline $6 / 6$ & 6 & 12 & 1 & 2 & 6 & 12 & \multirow{8}{*}{1.00} & \multirow{8}{*}{1.00} \\
\hline $6 / 9$ & 13 & 26 & 8 & 16 & 14 & 28 & & \\
\hline $6 / 12$ & 13 & 26 & 12 & 24 & 12 & 24 & & \\
\hline $6 / 18$ & 4 & 8 & 10 & 20 & 6 & 12 & & \\
\hline $6 / 24$ & 11 & 22 & 9 & 18 & 9 & 18 & & \\
\hline $6 / 36$ & 3 & 6 & 8 & 16 & 2 & 4 & & \\
\hline $6 / 60$ & 0 & 0 & 2 & 4 & 1 & 2 & & \\
\hline Total & 50 & 100 & 50 & 100 & 50 & 100 & & \\
\hline
\end{tabular}

The BCVA in the left eye showed decrease by one line during $1^{\text {st }}$ week of post laser treatment and during the final follow up at 6 months nearly 96 percent of patients regained their prelaser BCVA (Fig.6). As depicted in the Table.9, from the mean values and the $\mathrm{P}$ value calculated for the BCVA pre laser, $1^{\text {st }}$ week and 6 months in the left eye showed no significant difference.

\section{Discussion}

The mean age of the patients in our study was 57 years. Most of the patients in the study were in the age group between 51 and 60 years (44\%). Our study population had 31 Male patients $(62 \%)$ and 19 female patients (38\%). The mean age and gender distribution was observed to be similar to the studies conducted by ETDRS group ${ }^{3}$, Tewari, et $\mathrm{al}^{4}$, Shimura, et $\mathrm{al}^{5}$, Khan, et $\mathrm{al}^{6}$ and Sindhu, et $\mathrm{al}^{7}$.
In our study, out of the 31 male patients, 12 were between 51 and 60 years $(24 \%)$ and out of 19 female patients, 10 were between 51 and 60 years $(20 \%)$. The overall mean duration of diabetes mellitus was 11.8 years which was contrast to Seymenoglu, et $\mathrm{al}^{8}$ (14.1 years) and Sindhu, et $\mathrm{al}^{7}$ (14.4 years) studies.

Most of the patients included in our study had duration of diabetes between 6 and 10 years $(34 \%)$.

The pre laser ETDRS grading in the RE in our study population were SNPDR in $17(34 \%)$, VSNPDR in 19(38\%) and PDR in 14(28\%). The post laser ETDRS grading in the RE showed regression of hemorrhages and neovascularisation constituting MNPDR in 17(34\%), SNPDR in $17(34 \%)$, VSNPDR in $14(28 \%)$ and PDR in $2(4 \%)$. 
The pre laser ETDRS grading in the LE in our study population were SNPDR in $23(46 \%)$, VSNPDR in $16(32 \%)$ and PDR in $11(22 \%)$. The post laser ETDRS grading in the LE showed regression of hemorrhages and neovascularisation constituting MNPDR in 18(36\%), SNPDR in 21(42\%), VSNPDR in 7(14\%) and PDR in 4(8\%).

There was paucity of studies available in the literature mentioning the pre and post laser ETDRS grading in both right and left eyes.

The mean ETDRS score in the RE pre laser, post laser $1^{\text {st }}$ week and post laser 6 months were 67.60 , 60.20 and 67.10 respectively. The $\mathrm{P}$ value between pre laser and post laser $1^{\text {st }}$ week was 0.00 which was statistically significant. The $P$ value between pre laser and post laser 6 months was 0.32 which was not statistically significant. Thus the patients had initial decrease in BCVA in the $1^{\text {st }}$ week following laser which becomes stable following 6 months after treatment.

The mean ETDRS score in the LE pre laser, post laser $1^{\text {st }}$ week and post laser 6 months were 68.80 , 61.80 and 68.80 respectively. The $P$ value between pre laser and post laser $1^{\text {st }}$ week was 0.00 which was statistically significant. The $P$ value between pre laser and post laser 6 months was 1.00 which was not statistically significant. Thus the patients had initial decrease in BCVA in the $1^{\text {st }}$ week following laser which becomes stable following 6 months after treatment.

The mean BCVA of BE in our study population before laser treatment and after laser treatment at 6 months was $96 \%$ stable and only $4 \%$ showed decrease in BCVA due to persistence of PDR and they developed vitreous hemorrhage.

On comparing with other studies the visual outcome post laser PRP are as follows:

The stable BCVA was observed to be similar to the study conducted by Sindhu, et $\mathrm{al}^{7}$. In their study there was a drop in the mean BCVA at first follow up at 1 month than pre-PRP BCVA, which was statistically significant $(\mathrm{p}=0.01)$. There was no statistically significant difference in BCVA at follow up visits.
Shimura, et $\mathrm{al}^{5}$, compared the panretinal scatter photocoagulation efficacy at weekly/biweekly intervals prospectively. They observed that 36 diabetic patients had SNPDR and early PDR with good vision before laser therapy. Treatments after the follow-up for 12 weeks were analysed. The BCVA were maintained in $89 \%$ and $92 \%$ following PRP treatment at weekly and biweekly intervals respectively.

Our study was performed using Laser Indirect Ophthalmoscope (LIO) which was supported by Tinley et $\mathrm{al}^{9}$ who found that Indirect Ophthalmoscope (IDO) provides easier access to the peripheral retina and is more comfortable for patients. Hence PRP done using IDO is an alternative to slit lamp-based treatment and it can be done as an outpatient procedure.

\section{Conclusion}

PRP improves the prognosis of diabetic retinopathy by reducing the severity of progression thereby preventing vision threatening complications like advanced PDR leading to vitreous hemorrhage and retinal detachment.

Although new modalities of treatment for diabetic retinopathy like Anti-VEGF (Vascular Endothelial Growth Factor), IVTA (Intravitreal Triamcinolone) shows promising results PRP still proves to be the gold standard treatment of choice for diabetic retinopathy.

It is less invasive, cost effective and safe and can be done as an outpatient procedure without imposing the need for inpatient care and operating room usage.

\section{References}

1. Diabetic retinopathy. World Health Organization Priority eye diseases. Available from http://www.who.int/blindness/causes/priori ty/en/index $5 . h t m l$

2. Lee R, Wong TY, Sabanayagam C. Epidemiology of diabetic retinopathy, diabetic macular edema and related vision loss. Eye and Vision 2015;2(17):1-25. 
3. Royle P, Mistry H, Auguste P, Shyangdan D, Freeman K, Lois N, et al. Pan-retinal Photocoagulation and other forms of laser treatment and drug therapies for nonproliferative diabetic retinopathy: systematic review and economic evaluation. Health Technol Assess 2015;19(51):13-37.

4. Tewari HK, Ravindranath HM, Kumar A, Verma L. Diode laser scatter photocoagulation in diabetic retinopathy. Ann Ophthalmol 2000; 32:110-12.

5. Shimura M, Yasuda K, Nakazawa T, Kano T, Ohta S, Tamai M. Quantifying alterations of macular thickness before and after panretinal photocoagulation in patients with severe diabetic retinopathy and good vision. Ophthalmology 2003;110:2386-94.

6. Khan P, Tiwari SP, Pande S. Effect of Panretinal Photocoagulation on Visual Field and Macular Function in Diabetic Retinopathy. Sch J App Med Sci 2014;2(5F):1946-50.

7. Sindhu NM, Padmavathi P. Visual outcome following panretinal photocoagulation in proliferative diabetic retinopathy. J Evid Based Med Healthc 2018;5(2),164-8.

8. Seymenoglu RG, Ulusoy MO, Baser EF. Safety and efficacy of panretinal photocoagulation in patients with high-risk proliferative diabetic retinopathy using pattern scan laser versus conventional YAG laser. Kaohsiung J Med Sci 2016;32:22-6.

9. Tinley CG, Gray RH. Routine, single session, indirect laser for proliferative diabetic retinopathy. Eye 2009; 23:181923.

10. The Royal College of Ophthalmologists. Diabetic Retinopathy Guidelines 2012. Available from http://www.rcophth. ac.uk

11. Updated 2017 ICO Guidelines for Diabetic Eye Care. International council of ophthalmology.

Available

from http://www.icoph.org/ diabeticeyecare

12. Laser Management of Diabetic Retinopathy. In: Lasers in Ophthalmology A Practical Manual $2^{\text {nd }}$ edn: Kumar A, Kumar H, Dada T (eds), Jaypee Brothers Medical Publishers (P) Ltd, New Delhi 2005;pp17-27. 